\title{
Fear of the CS and of the context in two-way avoidance learning: Between- and within-subjects manipulations
}

\author{
EDWARD J. CALLEN \\ Northern Illinois University, DeKalb, Illinois
}

\begin{abstract}
The roles of CS fear and of context fear in signaled two-way avoidance learning were examined in two experiments in which shock intensity was manipulated either between or within subjects. For each subject, two discrete CSs, a light and a white noise, were used. For between-subjects comparisons, both CSs were paired with the same shock intensity, weak or strong. Under this condition, in which fear of the CSs and the context was greater with strong than with weak shock, avoidance performance varied inversely with shock intensity. For within-subjects comparisons, the light was paired with strong shock and the white noise with weak shock, or vice versa. In this case, context fear was constant during presentation of each CS, and avoidance performance varied directly with shock intensity. Additionally, intertrial responding was directly related to the amount of context fear. These results support effective reinforcement theory, an extension of two-factor theory, which acknowledges the contribution to avoidance learning both of CS fear and of context fear. The interchangeable effectiveness of visual and auditory stimuli as CSs is discussed with regard to stimulus specificity in avoidance learning.
\end{abstract}

One of the most reliable findings in the avoidancelearning literature is that in either a signaled or an unsignaled two-way avoidance task performance is better with weak than with strong shock at the levels of shock usually employed (e.g., Bauer, 1972; Cicala \& Kremer, 1969; Dieter, 1977; Johnson \& Church, 1965; D. E. McAllister, W. R. McAllister, \& Dieter, 1976; W. R. McAllister, D. E. McAllister, \& Douglass, 1971; Moyer \& Korn, 1964; Scoles, 1982/1983; Theios, Lynch, \& Lowe, 1966). This finding poses a difficulty for many theories of avoidance learning because generally it is assumed that the greater amount of fear that is conditioned with strong shock should lead to better avoidance learning.

A theory proposed in 1971 by W. R. McAllister et al. can, however, account for the inverse relationship and can also predict how certain variables can alter this relationship. Their effective reinforcement theory (see also W. R. McAllister, D. E. McAllister, Dieter, \& James, 1979 ) is an elaboration of Mowrer's (1947) two-factor theory of avoidance learning. The important role played by fear of the conditioned stimulus (CS) in accounting for two-way avoidance learning is acknowledged, but in addition, the contribution of the fear conditioned to the contextual cues is emphasized. When shock is received on escape trials during avoidance training, fear becomes con-

The experiments reported herein were supported in part by Grant $\mathrm{MH}$ 36610 from the National Institute of Mental Health awarded to Wallace R. McAllister and Dorothy E. McAllister, to whom the author is indebted for their valuable assistance throughout this research, and by a fellowship awarded to the author from Northern Illinois University. Requests for reprints should be sent to Edward J. Callen, Department of Psychology, Northern Illinois University, DeKalb, IL 60115. ditioned to both of these sources. On avoidance trials, when shock is not received, it is assumed that the effective reinforcement supporting the learning of the avoidance response is directly related to the amount of fear reduction occurring with the response but inversely related to the amount of fear present following the response. Typically, fear reduction would result primarily from CS termination but would also be produced by interoceptive or exteroceptive stimulus changes occurring with the instrumental response. The fear remaining after the response usually would be determined by the fear conditioned to the contextual cues. If the amount of fear of both the CS and the context increase equally, as presumably would occur with increases in shock intensity, it is assumed that the degrading effect of the increase in context fear present after the response is augmented relative to the facilitating effect of the increase in fear reduction occuring with CS termination in determining effective reinforcement. In other words, effective reinforcement is a relative concept. According to the theory, to achieve equal effective reinforcement as shock intensity (hence, fear) increases, the amount of fear reduction must be an increasingly greater proportion of the total amount of fear.

Construed in this way, an analogy can be drawn between effective reinforcement theory and Campbell's (1956) relative reinforcement difference limen of shock intensity. Campbell reported that as shock level increased, both the absolute and the proportional differences in shock-intensity reduction had to increase in order to produce equal reinforcement. Moreover, Campbell and Kraeling (1953) found better escape learning by rats trained to run from a $200-\mathrm{V}$ to a $100-\mathrm{V}$ shock than by those trained to run from a $400-\mathrm{V}$ to a $200-\mathrm{V}$ shock, even 
though the absolute amount of shock reduction was greater under the latter condition. As applied to a comparison of strong and weak shock in avoidance learning, the facilitating effect of a greater amount of fear reduction occurring with CS termination when shock is strong is more than offset by the degrading effect of a greater amount of context fear present after the instrumental response.

According to effective reinforcement theory, with CS fear held constant, any manipulation that effects an increase in fear of the contextual cues is predicted to degrade two-way avoidance performance, whereas any manipulation that decreases context fear should enhance performance. A number of studies provide support for these contentions. For example, increasing context fear with shock-alone trials has been demonstrated to deteriorate both signaled (Bloom \& Campbell, 1966) and unsignaled (Scoles, 1982/1983) two-way avoidance performance. Likewise, certain strategies have been employed which decrease contextual-cues fear, eventuating in a facilitation of performance. In a study by Dieter (1977), subjects were given four hours of nonreinforced preexposure to the contextual cues of the avoidance apparatus prior to two-way avoidance training. Presumably, the preexposure treatment allowed for latent inhibition to occur to the context, thereby attenuating the amount of fear that became conditioned to those cues during the subsequent avoidance training. With context fear reduced in this manner, performance was enhanced such that the typical inverse relationship between shock intensity and two-way avoidance performance was eliminated. W. R. McAllister et al. (1979) extended these findings by demonstrating not only that the inverse relationship was eliminated by attenuation of context fear with a preexposure treatment, but also that when training was extended, a direct relationship between shock intensity and avoidance performance was obtained. Finally, there are numerous examples of improvement in two-way avoidance performance resulting from a reduction in the amount of contextualcues fear present after the instrumental avoidance response. For instance, Kruger, Galvani, and Brown (1969) reported a significant improvement in learning when the compartment in which the subject remained after a response contained visual and tactual cues different from those in the starting compartment. Similarly, Modaresi (1975) found improved performance with the removal of the tactual cues following the instrumental response and D. E. McAllister et al. (1976) and W. R. McAllister et al. (1979) reported higher levels of performance if the response was followed by darkness, thereby eliminating the visual cues after the response. Taken together, these studies all illustrate the prominent role played by context fear in two-way avoidance learning.

With context fear held constant, effective reinforcement theory predicts that any experimental manipulation that decreases CS fear should degrade performance whereas any manipulation that increases CS fear should improve performance. These two propositions have received experimental support. Feldman (1977) and Hampton (1980/
1981) reported that the administration of nonreinforced preexposure to the discrete CS prior to two-way avoidance training, which presumably attenuated conditioning of fear to the CS (latent inhibition), produced inferior avoidance learning relative to that of nonpreexposed control subjects. W. R. McAllister, D. E. McAllister, Scoles, and James (1978) found that two-way avoidance performance was superior when CS fear was increased under conditions of constant context fear. In this study, subjects that received fear conditioning trials with the avoidance CS in a distinctly different context, prior to avoidance training, learned the instrumental avoidance response faster than did control subjects.

Effective reinforcement theory emphasizes the negative effect of context fear in accounting for the inverse relationship between shock intensity and two-way avoidance performance. It follows that if context fear is held constant as shock intensity is increased, a direct, rather than an inverse, relationship would be obtained. That is, as greater fear of the CS is conditioned with increases in shock intensity, effective reinforcement would likewise increase because the amount of fear reduction occurring with CS termination would be an increasingly greater proportion of the total amount of fear. One way to examine the effects of different levels of CS fear upon avoidance performance while holding context fear constant is to manipulate shock intensity within subjects. This means of investigation was adopted in the present studies.

\section{EXPERIMENT 1}

Previous investigations that have reported an inverse relationship between shock intensity and two-way avoidance learning have manipulated differences in shock intensity between subjects. Under these circumstances, subjects differ in the level of both CS fear and contextualcues fear. Experiment 1 was designed so that the effects on avoidance performance of two levels of shock intensity could be examined with either between-subjects or within-subjects comparisons. To this end, four groups of subjects were trained with two discrete stimuli, a light and a white noise, signaling either a weak or a strong shock. For two of the groups the shock intensity paired with each CS was constant, either weak or strong. Therefore, for these groups, it was expected that fear of each CS within a group would be equal but the amount of both CS fear and contextual-cues fear would differ between groups. For the other two groups the shock intensity paired with each CS differed; a weak shock was paired with the light CS and a strong shock was paired with the noise CS, or vice versa. In this case, in which shock intensity differed within subjects, context fear would be constant during presentation of each CS, but fear of the CSs would differ. Utilizing this type of design in which shock intensity is manipulated both between and within subjects provides a means to test predictions of effective reinforcement theory. Differences in shock intensity between subjects should result in an inverse relationship be- 
tween shock level and avoidance performance, whereas differences in shock intensity within subjects should yield a direct relationship.

\section{Method}

Subjects and Design. The subjects, 64 naive female hooded rats, 116-124 days of age, from the colony maintained by the Psychology Department of Northern Illinois University, were assigned randomly to one of four groups $(n=16)$. Ten additional subjects which avoided shock by perching on the hurdle were discarded, 7 from Group L(S)-N(W) and 3 from Group L(W)-N(W). The discard criterion was four trials of perching for at least $60 \mathrm{sec}$ each, two trials of perching for at least $100 \mathrm{sec}$ each, or one trial of perching for at least $200 \mathrm{sec}$. Food and water were available on an ad-lib basis in the home cage throughout the experiment.

The main experimental manipulation involved the intensity of shock paired with the two CSs during avoidance training. There were four experimental groups: $\mathrm{L}(\mathrm{W})-\mathrm{N}(\mathrm{W}), \mathrm{L}(\mathrm{S})-\mathrm{N}(\mathrm{S}), \mathrm{L}(\mathrm{W})$ $\mathrm{N}(\mathrm{S}), \mathrm{L}(\mathrm{S})-\mathrm{N}(\mathrm{W})$. The group designations indicate the shock intensity [weak (W) or strong (S)] that was paired with each CS [light (L) and white noise $(\mathrm{N})$ ] during avoidance training. Thus, two of these groups had the same intensity of shock paired with each CS. For Group L(W)-N(W), both the light and noise were paired with weak shock, whereas for another group, $\mathrm{L}(\mathrm{S})-\mathrm{N}(\mathrm{S})$, both the light and noise were paired with strong shock. For each of the remaining two groups, one CS was paired with strong shock and the other CS was paired with weak shock. For Group L(W)-N(S), the light signaled a weak shock and the noise signaled a strong shock; for Group $\mathrm{L}(\mathrm{S})-\mathrm{N}(\mathrm{W})$, the pairings were reversed.

Apparatus. The apparatus used was a Lehigh Valley shuttlebox (Model 146-04), measuring $450 \mathrm{~mm}$ long $\times 200 \mathrm{~mm}$ wide $\times$ $200 \mathrm{~mm}$ high, enclosed in a lightproof, sound-attenuating chamber. The shuttlebox was divided into two identical compartments by a $25-\mathrm{mm}$-high metal partition, with each compartment containing an end wall constructed of aluminum and with the top and side walls constructed of clear Plexiglas. The grid floor of each compartment consisted of 20 stainless steel rods, each $2.4 \mathrm{~mm}$ in diameter, spaced $11 \mathrm{~mm}$ apart (center to center). One 28-V lamp covered by a jeweled lens, $13 \mathrm{~mm}$ in diameter, was laterally centered on each end wall $140 \mathrm{~mm}$ above the grid floor. These lamps provided a constant illumination of $13 \mathrm{~lx}$. Responses and latencies were recorded by a Coulbourn printing counter (Model R22-10) when the subject locomoted from one compartment to the other, causing the floor to tilt slightly and to activate a microswitch. Scrambled shock was delivered through the grid floor by one of two BRS/LVE Model SGS-004 shock generators. The white-noise CS was provided by a Grason-Stadler white-noise generator, Model $901 \mathrm{~B}$, which increased the ambient noise level in the apparatus from 72 to $82 \mathrm{~dB}, \mathrm{C}$ scale. The illumination for the light CS was provided by two light boxes, each positioned behind an end wall of the shuttlebox $335 \mathrm{~mm}$ above the grid tloor. Each light box contained six 28-V bulbs which provided for an increase in illumination from $13 \mathrm{~lx}$ (intertrial illumination) to $234 \mathrm{~lx}$.

Procedure. The experiment was conducted over 2 consecutive days, and approximately $24 \mathrm{~h}$ intervened between the experimental treatments. On the day prior to the start of the experiment, the subjects were transported from the colony room to the laboratory animal room, where they were housed in pairs for the duration of the experiment.

During each experimental session, 100 signaled, two-way avoidance trials were administered. Each trial began with the presentation of either the light or noise CS. The stimulus presented on each trial was randomly determined by a Coulbourn probability generator (Model S35-20), programmed on a 50\% probability schedule. The unconditioned stimulus (UCS), either a 54-V dc (weak) or a 99-V dc (strong) shock, depending upon the stimulus and group designation, was presented if the subject did not activate the microswitch by locomoting to the other compartment within $5 \mathrm{sec}$ following CS onset. An escape response following shock onset terminated the CS and the UCS, whereas an avoidance response that occurred during the 5-sec CS-UCS interval terminated the CS and prevented shock. After a 30-sec intertrial interval, during which the subject was free to respond, the next trial was begun. Latencies were measured, in $0.1 \mathrm{sec}$, from the onset of the CS to the depression of the floor in the opposite compartment.

\section{Results}

Analyses were performed on the percentage of avoidances made to each CS and on the number of responses made during the intertrial intervals. Two major sets of analyses were performed on these measures. One series compared the performance of the two groups in which shock intensity differed between subjects [Groups $\mathrm{L}(\mathrm{W})-\mathrm{N}(\mathrm{W})$ and $\mathrm{L}(\mathrm{S})-\mathrm{N}(\mathrm{S})$ ]. For these two groups, in which context fear differed between subjects, avoidance performance should be better to the CSs paired with weak shock than to the CSs paired with strong shock (the inverse relationship). A second set of analyses compared the performance of the two groups in which shock intensity differed within subjects [Groups L(W)-N(S) and L(S)$\mathrm{N}(\mathrm{W})]$. For these two groups, in which context fear was held constant within subjects, avoidance performance should be better to the CS paired with strong shock than to the CS paired with weak shock (a direct relationship). Finally, the number of responses made during the intertrial intervals were analyzed, the assumption being that responding would be a direct function of the level of context fear.

Avoidance responding. Figure 1 presents the mean percentage of avoidances to each CS, in blocks of 20 trials, for the two groups in which both CSs were paired with the same intensity of shock. Two findings should be noted. First, the expected inverse relationship was obtained. That is, Group $L(W)-N(W)$, which had a weaker shock intensity paired with each CS, performed better than the group that had both CSs paired with strong shock, Group L(S)$N(S)$. Second, performance with the noise CS tended to be superior to that with the light CS early in training for both of the groups.

These impressions were confirmed by the results of statistical analyses. A mixed-design repeated measures ANOVA of the percentage of avoidances to each CS in blocks of 20 trials was computed separately for each day, with groups treated as the between-subjects factor and stimulus and trial blocks as the within-subjects factors. On Day 1, the effect of groups was significant $[F(1,30)$ $=5.21, p<.05]$, reflecting the superior avoidance performance to each CS in Group $\mathrm{L}(\mathrm{W})-\mathrm{N}(\mathrm{W})$ relative to Group L(S)-N(S). Also, the effect of trial blocks was significant $[F(4,120)=25.53, p<.001]$, as was the stimulus $\times$ trial blocks interaction $[F(4,120)=4.06, p<.005]$ and the triple interaction $[F(4,120)=3.27, p<.05]$. Because of these interactions, simple effects withinsubjects ANOVAs were computed separately for each group. For Group L(W)-N(W), the analysis yielded a significant effect of trial blocks $[F(4,60)=25.49, p<.001]$ and a significant stimulus $\times$ trial blocks interaction 


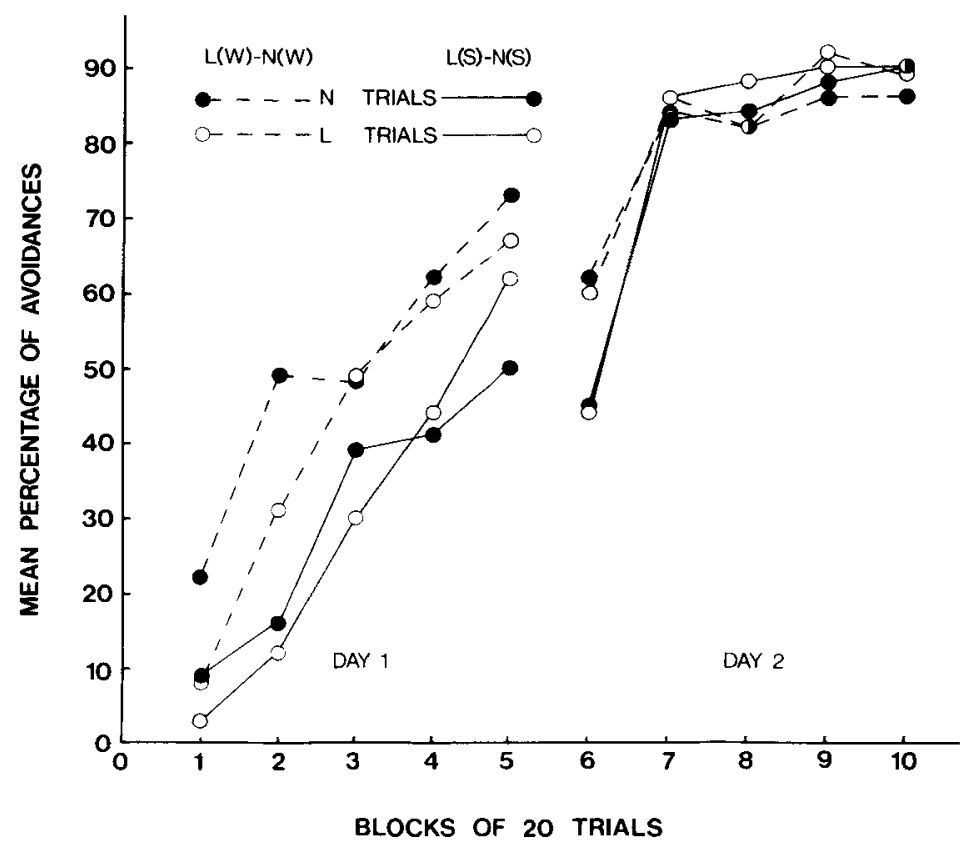

Figure 1. Experiment 1. Mean percentage of avoidances to each $\mathrm{CS}$ as a function of blocks of 20 trials for Groups $L(W)-N(W)$ and $L(S)-N(S)$.

$[F(4,60)=3.20, p<.05]$, reflecting the better performance to the noise CS than to the light CS on only the first two trial blocks. For Group L(S)-N(S), the effect of trial blocks $[F(4,60)=26.89, p<.001]$ was significant, as was the interaction of trial blocks with stimulus $[F(4,60)$ $=4.51, p<.005]$, which resulted from the crossover in the curves for the two stimuli.

Analysis of performance on Day 2 yielded a significant effect of trial blocks $[F(4,120)=47.70, p<.001]$ and a significant groups $\times$ trial blocks interaction $[F(4,120)$ $=4.30, p<.005]$, the latter reflecting the better performance with weak shock [Group $L(W)-N(W)$ ] than with strong shock [Group $\mathrm{L}(\mathrm{S})-\mathrm{N}(\mathrm{S})$ ] on only the first trial block. No effect of stimulus was found on this day.

The avoidance-learning data for the two groups that had a different shock intensity paired with each CS, Groups $\mathrm{L}(\mathrm{W})-\mathrm{N}(\mathrm{S})$ and $\mathrm{L}(\mathrm{S})-\mathrm{N}(\mathrm{W})$, are illustrated in Figure 2. In the upper panel of the figure, it is clear that, for the group that had the light paired with weak shock and the noise paired with strong shock [Group L(W)-N(S)], there was a direct relationship between shock intensity and performance; avoidance responding was consistently better to the noise than to the light. However, as may be seen in the lower panel of Figure 2, when the light was paired with strong shock and the noise was paired with weak shock [Group L(S)-N(W)], neither a direct nor an inverse relationship was obtained; avoidance responding to the two stimuli was highly similar.

Statistical analyses supported these observations. A mixed-design repeated measures ANOVA on Day 1 resulted in a significant effect of stimulus $[F(1,30)=4.02$, $p=.05]$ and of trial blocks $[F(4,120)=16.22, p<.001]$. The groups $\times$ stimulus interaction approached sig- nificance $[F(1,30)=3.24, p=.08]$. Analysis of performance within each group revealed that for Group L(W)$\mathrm{N}(S)$ there were significant effects of stimulus $[F(1,15)$ $=35.46, p<.001]$ and trial blocks $[F(4,60)=26.54$, $p<.001]$. Avoidance performance to the noise CS, which was paired with strong shock, was better than that to the light CS, which was paired with weak shock. However, in Group L(S)-N(W), only the effect of trial blocks was reliable $[F(4,60)=17.19, p<.001]$. Neither the stimulus effect nor the interaction attained significance, indicating the similarity of avoidance responding to the two CSs in this group.

A similar pattern of results was found on Day 2. Statistical analysis revealed a significant effect of trial blocks $[F(4,120)=35.15, p<.001]$ and of groups $[F(1,30)$ $=5.34, p<.05$ ], the latter reflecting the superior performance of Group L(W)-N(S). The stimulus $\times$ groups interaction was also reliable $[F(1,30)=16.21, p<.001]$. Follow-up analyses revealed that, for Group L(W)-N(S), the effect of stimulus $[F(1,15)=30.09, p<.001]$, trial blocks $[F(4,60)=36.37, p<.001]$, and the interaction of these two factors $[F(4,60)=2.58, p<.05]$ were all significant. In this group, the noise $C S$ led to better avoidance performance than did the light CS, although the curves tended to converge with trials. However, for Group L(S)-N(W), as was the case on Day 1, responding to the two stimuli did not differ significantly. Only the effect of trial blocks reached statistical significance $[F(4,60)=31.36, p<.001]$.

Intertrial responding. The top portion of Figure 3 presents the mean number of intertrial responses (ITRs) in blocks of 20 trials for the two groups in which both CSs were paired with the same intensity of shock. For 

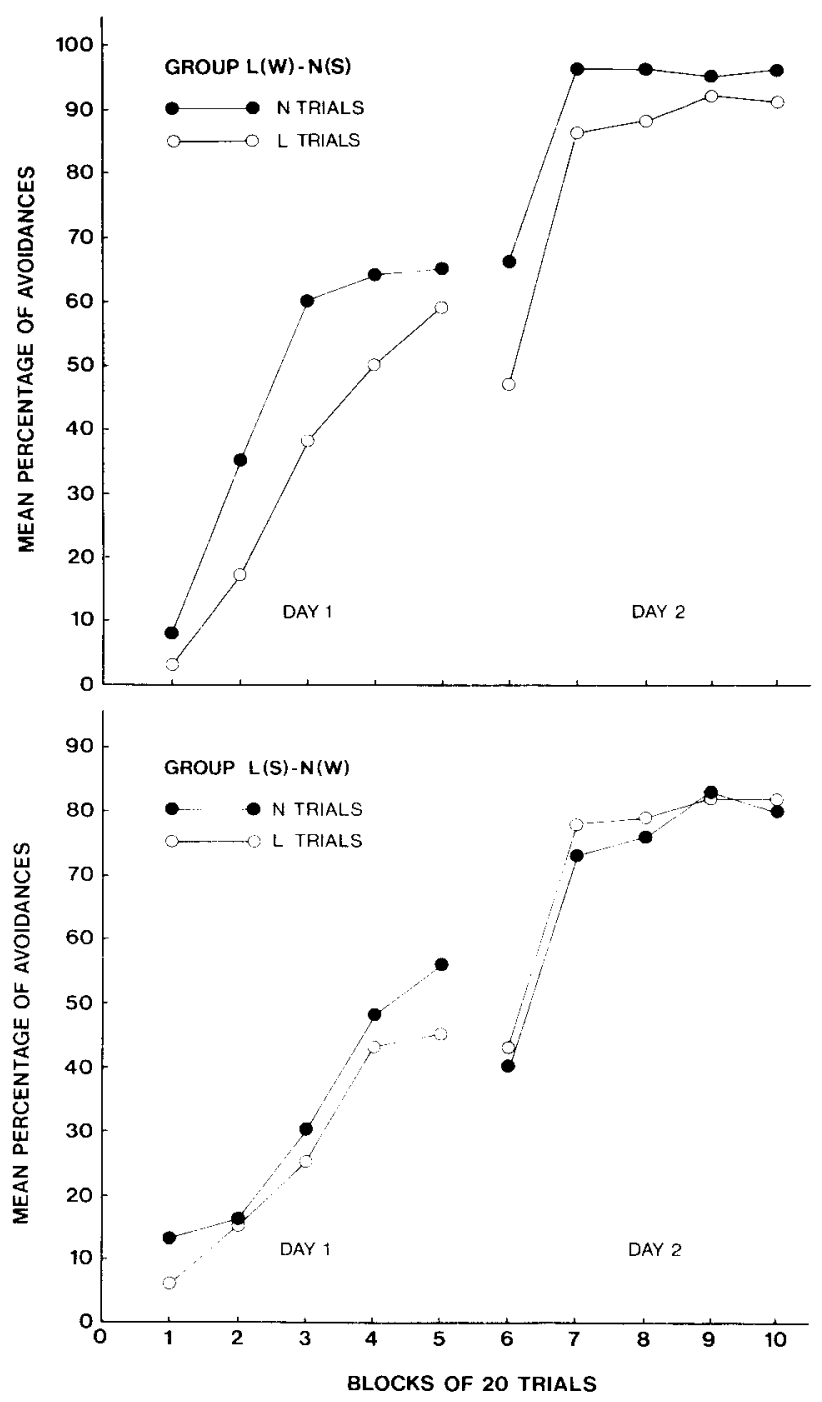

Figure 2. Experiment 1. Mean percentage of avoidances to each CS as a function of blocks of 20 trials for Group L(W)-N(S) (upper panel) and Group $L(S)-N(W)$ (lower panel).

both groups, the mean number of ITRs increased with training. In contrast to avoidance responding, intertrial responding and shock intensity were directly related when shock intensity differed between subjects. The group that had strong shock paired with each CS, and therefore had more context fear, Group L(S)-N(S), exhibited more intertrial responding than the group that had weak shock paired with each CS, Group L(W)-N(W).

These impressions were supported by statistical analyses. A repeated measures ANOVA on Day 1 yielded a significant effect of trial blocks $[F(4,120)=4.53, p<$ $.005]$ and a significant groups $\times$ trial blocks interaction $[F(4,120)=4.52, p<.005]$. This reliable interaction resulted from the increasingly greater number of ITRs over trial blocks in the strong-shock group relative to the weak-shock group. As can be seen in the figure, the same differential effect of shock level was evident on Day 2 , on which the effect of trial blocks $[F(4,120)=4.56, p<$ $.005]$ and the interaction $[F(4,120)=5.44, p<.001]$ were again significant.

A similar analysis was performed for the groups that had an overall equal level of shock intensity, and therefore of context fear, Groups $\mathrm{L}(\mathrm{W})-\mathrm{N}(\mathrm{S})$ and $\mathrm{L}(\mathrm{S})-\mathrm{N}(\mathrm{W})$. The ITR data for these two groups are presented in the bottom portion of Figure 3. An ANOVA for each day revealed significant effects only for trial blocks $[F \mathrm{~s}(4,120)$ $=7.41$ and 8.89 for Days 1 and 2, respectively, ps $<.001$ ], reflecting the increase in the number of ITRs with avoidance training. Neither the effect of groups nor the groups $\times$ trial blocks interaction reached significance on either day (all $F_{\mathrm{S}}<1$ ), indicating that when context fear was equated between groups, the patterns of intertrial responding were similar.

\section{Discussion}

The present study provides data congruous with the notion of effective reinforcement theory that both CS fear and contextual-cues fear play an important role in twoway avoidance learning. When the level of shock intensity differed between subjects, producing different levels of context fear, performance was better with weak than with strong shock. That is, Group L(W)-N(W) learned the avoidance response faster than did Group L(S)-N(S). A different pattern of results obtained when the overall level of shock intensity, and therefore the amount of contextual-cues fear, between subjects was held constant, but the level of shock intensity paired with each CS was varied within subjects [Groups $L(W)-N(S)$ and $L(S)$ $\mathrm{N}(\mathrm{W})]$. In this case, the usual inverse relationship was eliminated in both groups and a direct relationship was obtained between shock intensity and avoidance performance in Group $L(W)-N(S)$. That is, subjects in this group performed significantly better to the noise CS, which was paired with strong shock, than to the light CS, which was paired with weak shock. Because the noise was paired with stronger shock, more fear presumably became conditioned to it than to the light, and therefore, more reinforcement (fear reduction) took place with termination of the noise CS following the instrumental avoidance response.

On the other hand, when the light CS was paired with strong shock and the noise CS was paired with weak shock [Group L(S)-N(W)], with context fear held constant, neither an inverse nor a direct relationship was obtained; responding to the two stimuli did not differ. A likely reason for the failure to obtain a direct relationship in Group $\mathrm{L}(\mathrm{S})-\mathrm{N}(\mathrm{W})$ is that the salience of the two stimuli was not equated in this experiment. A suggestion that this may have been so is indicated by the tendency for performance early in training to be better to the noise than to the light in the two groups that had both CSs paired with one level of shock [Groups $\mathrm{L}(\mathrm{W})-\mathrm{N}(\mathrm{W})$ and $\mathrm{L}(\mathrm{S})-\mathrm{N}(\mathrm{S})$ ]. If there was a salience difference, the direct relationship obtained in Group $L(W)-N(S)$ could have resulted from two factors: the noise being paired with strong shock and the noise being more salient. Moreover, in the group in which the 

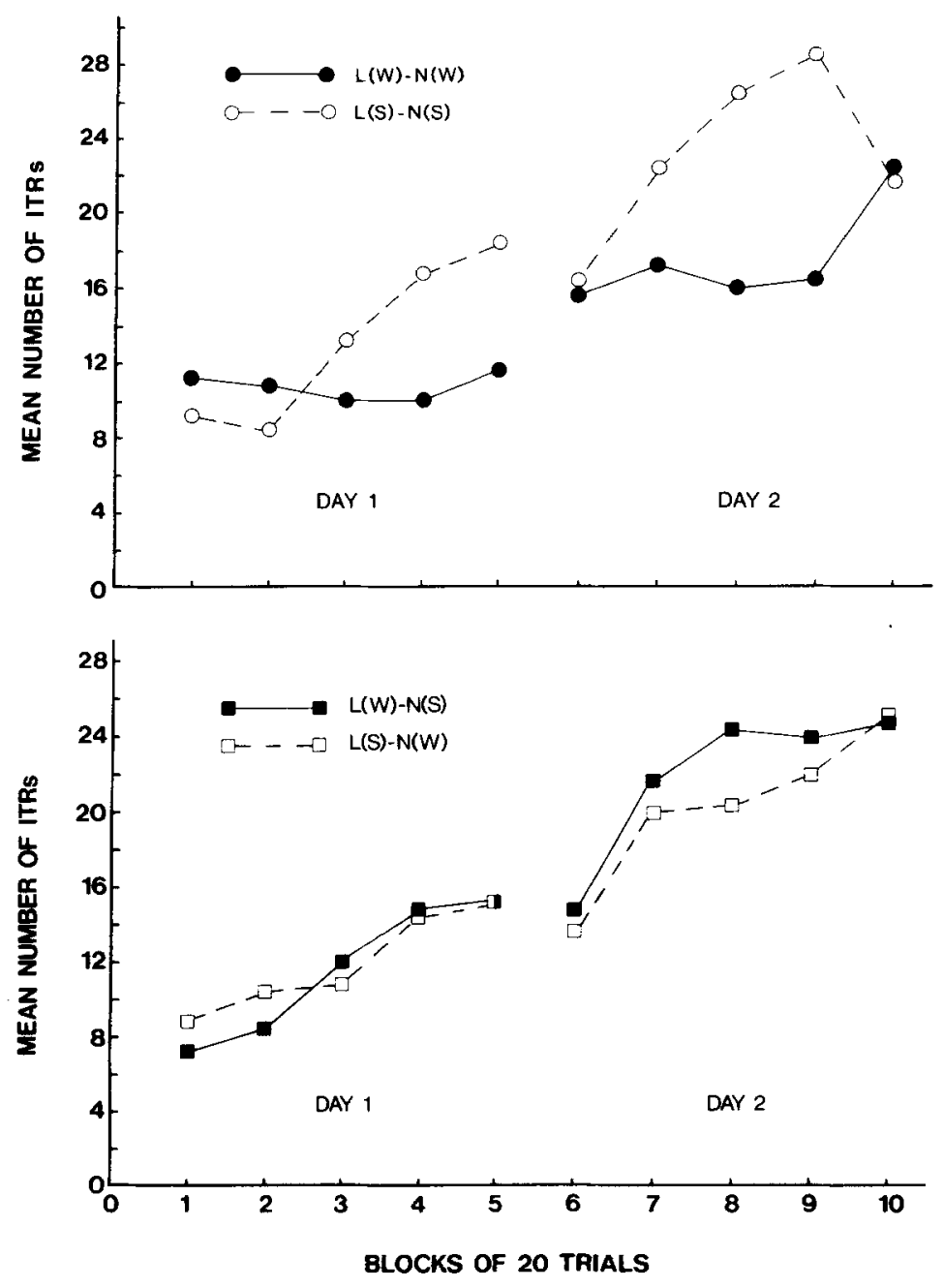

Figure 3. Experiment 1. Mean number of intertrial responses (ITRs) as a function of blocks of 20 trials for Groups $L(W)-N(W)$ and $L(S)-N(S)$ (upper panel) and for Groups $L(W)-N(S)$ and $L(S)-N(W)$ (lower panel).

light was paired with strong shock and the noise was paired with weak shock, this difference in salience could have masked the expected better performance to the light.

This study also demonstrated that the amount of contextual-cues fear was related to the degree of intertrial responding (cf. Mowrer \& Lamoreaux, 1951). Subjects that received training only with strong shock [Group $\mathrm{L}(\mathrm{S})-\mathrm{N}(\mathrm{S})]$ exhibited more intertrial responding than those that received training only with weak shock [Group L(W)$\mathrm{N}(\mathrm{W})]$. Thus, there was a direct relationship between the level of context fear and the number of ITRs. However, when fear of the context did not differ between groups [Groups $\mathrm{L}(\mathrm{W})-\mathrm{N}(\mathrm{S})$ and $\mathrm{L}(\mathrm{S})-\mathrm{N}(\mathrm{W})$ ], there was no difference in intertrial responding. Also supporting the notion that context fear is a determinant of intertrial responding is the finding that ITRs increased as a function of trials (see Figure 3). If more avoidance training had been ad- ministered, a decrease in intertrial responding would be predicted because of the decrease in context fear as subjects learn to discriminate between the CS plus contextual cues and the contextual cues alone (W. R. McAllister, D. E. McAllister, \& Benton, 1983).

\section{EXPERIMENT 2}

In Experiment 2 an attempt was made to minimize the difference in salience between the light and noise CSs. In each of two groups, one CS was paired with strong shock and the other was paired with weak shock.

\section{Method}

Subjects and Design. The subjects, 32 naive female hooded rats, 116-122 days of age, from the same source as those in the first experiment, were assigned randomly to one of two groups $(n=16)$. Sixteen additional subjects that avoided shock by perching on the 
hurdle were discarded, using the same criterion as in Experiment 1, 10 from Group $L(W)-N(S)$ and 6 from Group $L(S)-N(W)$. The subjects were maintained as in Experiment 1.

The two groups of this study, designated as $L(W)-N(S)$ and $L(S)-$ $N(W)$, replicated those of Experiment 1 .

Apparatus and Procedure. This experiment employed the same apparatus as in Experiment 1, except that the intensity of the whitenoise CS was decreased so that its presentation increased the ambient noise level in the apparatus from 74 to $78 \mathrm{~dB}, \mathrm{C}$ scale. Additionally, the intensity of the light CS was increased, providing an increase in illumination from $12 \mathrm{~lx}$ (intertrial illumination) to $352 \mathrm{~lx}$.

All procedures were the same as for the analogous groups in Experiment 1 .

\section{Results and Discussion}

Avoidance responding. The mean percentage of avoidances to each CS in blocks of 20 trials is presented in Figure 4. It is clear that within-subject differences in the shock intensity paired with each CS resulted in a direct relationship between shock intensity and avoidance performance for both groups. The upper portion of Figure 4 shows that subjects in Group $\mathrm{L}(\mathrm{W})-\mathrm{N}(\mathrm{S})$ made more avoidances to the noise, which was paired with strong shock, than to the light, which was paired with weak shock. Conversely, as shown in the lower portion of the
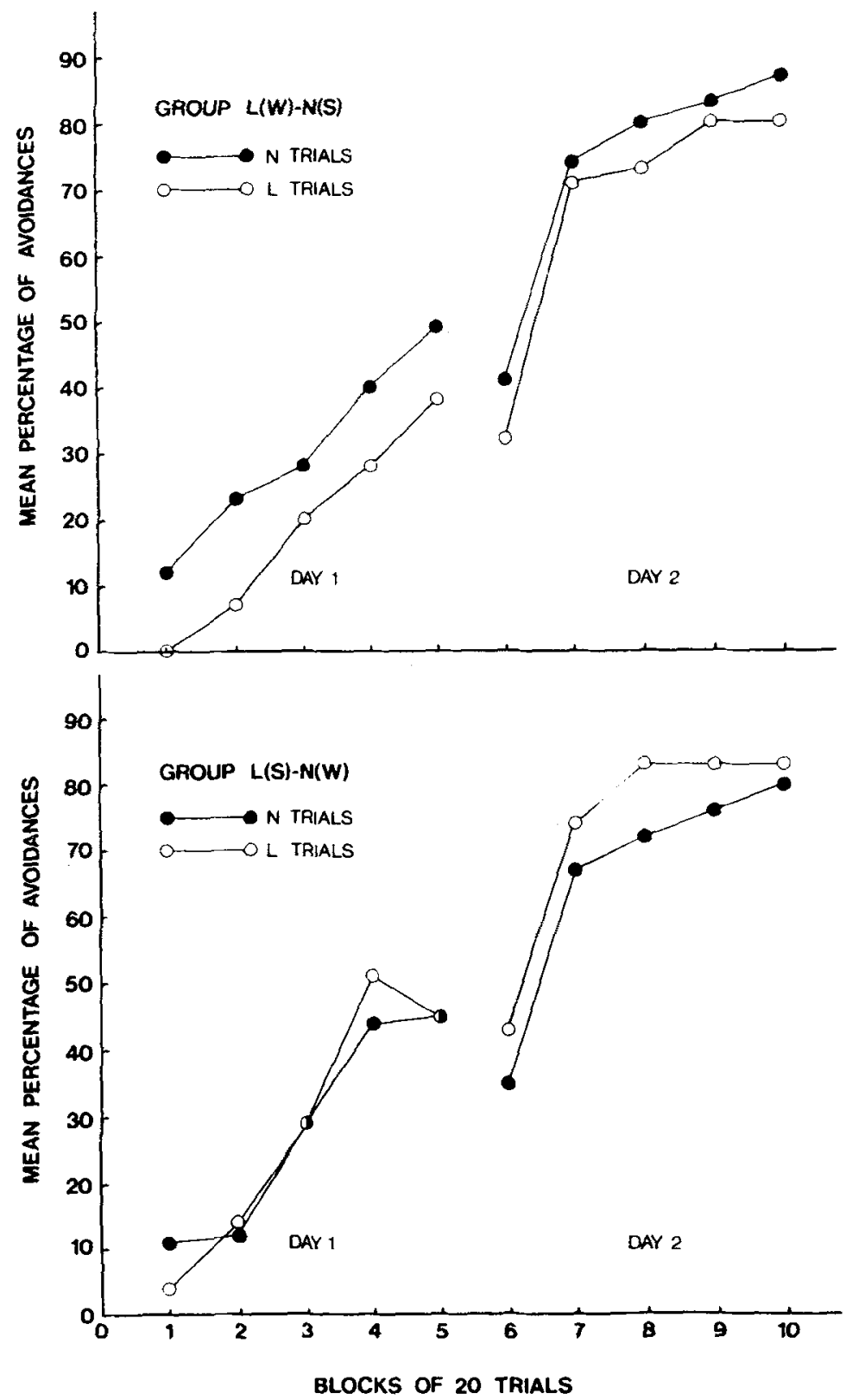

Figure 4. Experiment 2. Mean percentage of avoidances to each $\mathrm{CS}$ as a function of blocks of 20 trials for Group $L(W)-N(S)$ (upper panel) and Group $L(S)$ $\mathrm{N}(\mathrm{W})$ (lower panel). 


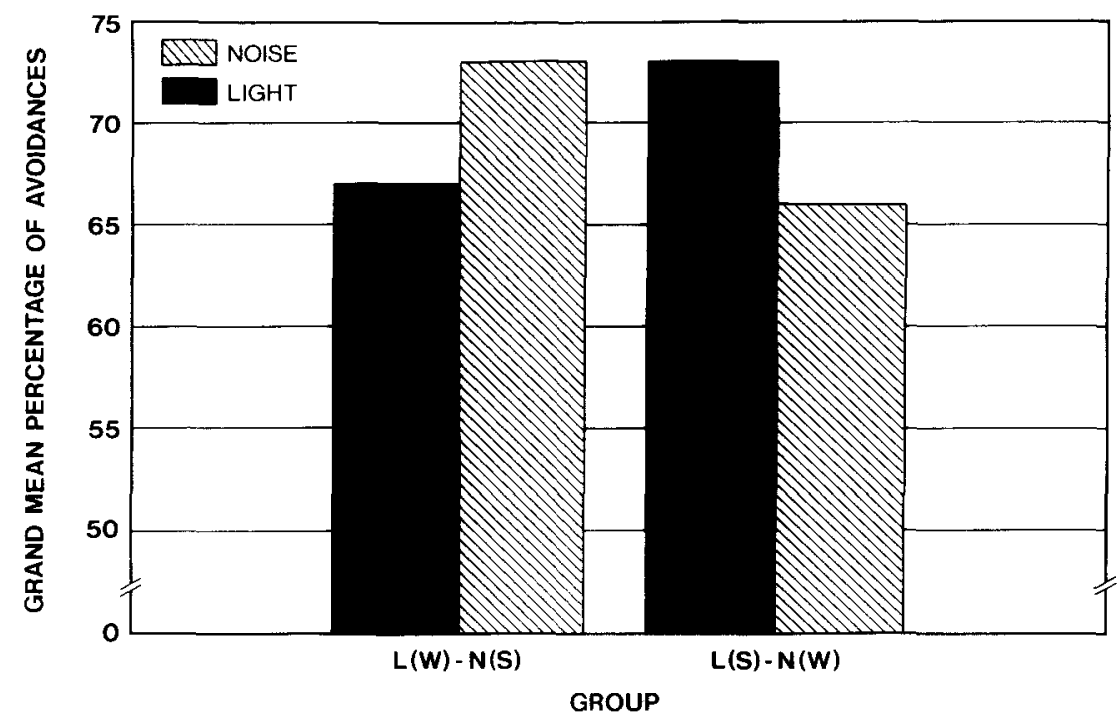

Figure 5. Experiment 2. Grand mean percentage of avoidances to each $\mathrm{CS}$ on the 2 nd day of training for Groups $L(W)-N(S)$ and $L(S)-N(W)$.

figure, subjects in Group L(S)-N(W) avoided more often to the light, which in this case was paired with strong shock, than to the noise, which was paired with weak shock. These direct relationships are summarized in Figure 5, which presents the grand mean percentage of avoidances to each CS on the 2nd day of training for each of the groups. That the difference in salience between the two stimuli was minimized is indicated by the similarity between the groups with respect to the magnitude of the difference in responding between the CS paired with strong shock and the CS paired with weak shock.

These impressions were confirmed statistically. A mixed-design repeated measures ANOVA was performed on the percentage of avoidances to each CS, with groups as the between-subjects factor and stimulus and trial blocks as the within-subjects factors. On Day 1, this analysis yielded significant effects of stimulus $[F(1,30)=10.40$, $p<.005]$ and trial blocks $[F(4,120)=25.58, p<.001]$, and a significant stimulus $\times$ groups interaction $[F(1,30)$ $=11.53, p<.005]$. No other effects were significant. Follow-up within-subjects ANOVAs for each group revealed that, in Group $\mathrm{L}(\mathrm{W})-\mathrm{N}(\mathrm{S})$, there were significant effects of trial blocks $[F(4,60)=14.87, p<.001]$ and stimulus $[F(1,15)=17.82, p<.001]$, the latter reflecting the better performance to the noise CS, which was paired with strong shock, than to the light $C S$, which was paired with weak shock. In Group $\mathrm{L}(\mathrm{S})-\mathrm{N}(\mathrm{W})$, only the effect of trial blocks reached significance $[F(4,60)=$ $12.27, \mathrm{p}<.001]$

On Day 2, the effect of trial blocks $[F(4,120)=53.63$, $p<.001]$ and the stimulus $\times$ groups interaction $[F(1,30)$ $=11.90, p<.005]$ were significant. Follow-up analyses revealed a significant effect of trial blocks $[F(4,60)=$ $37.54, p<.001]$ and a marginal effect of stimulus $[F(1,15)=3.60, p=.077]$ for Group $\mathrm{L}(\mathrm{W})-\mathrm{N}(\mathrm{S})$. For Group L(S)-N(W), the effects of both trial blocks $[F(4,60)$
$=20.16, p<.001]$ and stimulus $[F(1,15)=11.10, p<$ $.005]$ were reliable, the latter reflecting the better avoidance performance to the light CS, which was paired with strong shock, than to the noise CS, which was paired with weak shock.

Intertrial responding. As was the case in Experiment 1 , an overall equal level of shock intensity resulted in an equivalent amount of intertrial responding by Groups $\mathrm{L}(\mathrm{W})-\mathrm{N}(\mathrm{S})$ and $\mathrm{L}(\mathrm{S})-\mathrm{N}(\mathrm{W})$. The mean number of ITRs for each block of 20 trials was 8.31, 8.44, 11.38, 14.31, $14.31,15.06,18.88,22.75,22.56$, and 24.56 for Group $\mathrm{L}(\mathrm{W})-\mathrm{N}(\mathrm{S})$ and $9.38,8.50,12.81,15.25,16.50$, $17.88,24.25,24.75,27.69$, and 25.44 for Group L(S)$\mathrm{N}(\mathrm{W})$. Statistical analysis revealed that, on each day, only the effect of trial blocks was significant $[F s(4,120)=$ 11.56 and 7.51 for Days 1 and 2, respectively, ps $<.001$ ], reflecting the increase in the number of ITRs with training for both groups.

\section{GENERAL DISCUSSION}

The present two studies have demonstrated the important roles that fear both of the discrete CS and of the context play in a signaled two-way avoidance learning situation. When fear of the contextual cues differed between subjects, an inverse relationship was obtained between shock intensity and avoidance performance. When context fear was held constant within subjects, a direct relationship was obtained. In addition, more intertrial responding, presumably a reflection of greater contextualcues fear, was observed with strong than with weak shock.

A direct relationship between shock intensity and twoway avoidance performance was also reported by $\mathbf{W}$. R. McAllister et al. (1979). These investigators administered nonreinforced preexposure to the contextual cues prior to avoidance training with either strong or weak shock. 
The preexposure treatment attenuated the amount of fear that became conditioned to the contextual cues during avoidance training (latent inhibition) and reduced the degrading influence of this source of fear upon performance in the strong-shock group. Therefore, more effective reinforcement occurred with strong than with weak shock. A different way of minimizing the differential effect of context fear on avoidance performance when shock intensity is varied was undertaken in the present studies. Because each subject received training with two CSs, one paired with strong shock and one with weak shock, context fear was constant during the presentation of each CS. Thus, effective reinforcement was greater with strong shock because the amount of fear reduction occurring with CS termination constituted a greater proportion of the total amount of fear, and, as expected, avoidance performance was directly related to shock intensity. Results compatible with these findings were also reported by Bintz (1971), who utilized a design similar to the second experiment presented here. With goldfish as subjects, Bintz found better avoidance performance with strong than with weak shock.

The findings of the present studies are problematic for other theorists who have offered explanations of the inverse relationship between shock intensity and two-way avoidance performance. For example, a competing-response explanation (e.g., Theios et al., 1966) assumes that, with stronger shock, there is an increase in the frequency of competing responses, such as freezing or staying. These competing responses then interfere with successful avoidance responding. The finding of a direct relationship between shock intensity and avoidance performance, with context fear held constant, clearly is not congruent with this point of view. According to the competing-response interpretation, the CS paired with strong shock should have evoked responses incompatible with the instrumental avoidance response and learning should have been poorer to that CS than to the CS paired with weak shock. D'Amato and his colleagues (e.g., D'Amato, Etkin, \& Fazzaro, 1968; D'Amato, Fazzaro, \& Etkin, 1968) have also proposed an explanation of the inverse relationship between avoidance performance and shock intensity. According to their theory, performance in an avoidance task depends upon the making of anticipatory responses and the discrimination of the avoidance contingency. Anticipatory responses that occur during the CS-UCS interval presumably allow the subject to discriminate the avoidance contingency. Because more anticipatory responses occur with weak than with strong shock (e.g., D'Amato, Etkin, \& Fazzaro, 1968), the avoidance contingency is, according to this position, discriminated sooner with weaker shock, and hence, the inverse relationship is found. The present findings are, however, inconsistent with this interpretation. When shock intensity was varied within subjects, a direct relationship between avoidance performance and shock level was obtained although, according to D'Amato's theory, subjects should have discriminated the avoidance contingency faster to the CS paired with weak shock than to the CS paired with strong shock. This theory also has problems accounting for the fact that preexposure to the contextual cues prior to avoidance training also produces a direct relationship (W. R. McAllister et al., 1979).

Additionally, it would seem that other more cognitive positions, such as those espoused by Bolles (1972) and by Seligman and Johnston (1973), which claim that avoidance learning is dependent upon the formation of expectancies of safety and of shock, would have difficulty in accounting for the between- and within-subjects effects of shock intensity that were found in the present studies. As currently formulated, these theories make no provisions for the interaction of CS fear and contextual-cues fear in avoidance learning. It appears that effective reinforcement theory is the only extant theory of avoidance learning that can account not only for the inverse relationship between avoidance performance and shock intensity obtained when shock differs between subjects, but also for the direct relationship obtained either when shock intensity is manipulated within subjects or when the amount of contextual-cues fear is reduced by a preexposure treatment.

It should be noted that the present studies provide data that are discordant with the position adopted by certain theorists that there are constraints on what a rat can learn in an avoidance situation. For instance, Jacobs and LoLordo $(1977,1980)$ have proposed that a change in the level of illumination is an ineffective warning signal (CS) for a rat in an avoidance-learning task, whereas an auditory stimulus is a highly effective CS. This proposition was based chiefly on demonstrations that a light that had been paired with shock did not produce an increase in Sidman-avoidance responding although an increase in baseline response rates was consistently obtained with an auditory stimulus. In the first experiment reported here, the avoidance performance of rats to the light CS was essentially the same as that to the noise CS within Groups $\mathrm{L}(\mathrm{W})-\mathrm{N}(\mathrm{W})$ and $\mathrm{L}(\mathrm{S})-\mathrm{N}(\mathrm{S})$. This finding joins that of Cicala and Azorlosa (1985, Experiment 1), who reported similar avoidance learning between groups trained with a light CS and those trained with a white-noise CS. Moreover, when the salience of the two stimuli was more nearly equated in the second experiment presented here, avoidance performance to the light CS was better than that to the noise CS in the group that had the light paired with strong shock and the noise paired with weak shock. Furthermore, the converse was obtained when the noise CS was paired with strong shock and the light CS with weak shock; superior avoidance performance occurred to the noise. In other words, the level of avoidance responding did not depend on CS modality but rather on the intensity of shock that was paired with a particular CS. Thus, the present data do not corroborate the Jacobs and 
LoLordo hypothesis and suggest that, at least under some circumstances, such "constraints," when found, may simply reflect differences in salience between stimuli.

\section{REFERENCES}

BAUER, R. H. (1972). The effects of CS and US intensity on shuttlebox avoidance. Psychonomic Science, 27, 266-268.

BiNTZ, J. (1971). Between- and within-subject effect of shock intensity on avoidance in goldfish (Carassius auratus). Journal of Comparative \& Physiological Psychology, 75, 92-97.

BLoom, J. M., \& CAMPBELL, B. A. (1966). Effects of CS omission following avoidance learning. Joumal of Experimental Psychology, 72, 36-39.

Bolles, R. C. (1972). Reinforcement, expectancy, and learning. Psychological Review, 79, 394-409.

CAMPBELL, B. A. (1956). The reinforcement difference limen (RDL) function for shock reduction. Journal of Experimental Psychology, 52, 258-262.

Campbell, B. A., \& Kraeling, D. (1953). Response strength as a function of drive level and amount of drive reduction. Journal of Experimental Psychology, 45, 97-101.

Cicala, G. A., \& Azorlosa, J. L. (1985). Stimulus specificity in avoidance learning. Learning \& Motivation, 16, 83-94.

Cicala, G. A., \& Kremer, E. (1969). The effects of shock intensity and d-amphetamine on avoidance learning. Psychonomic Science, 14, $41-42$.

D'Amato, M. D., Etkin, M., \& Fazzaro, J. (1968). Effects of shock type and intensity on anticipatory responses. Journal of Comparative \& Physiological Psychology, 66, 527-529.

D'Amato, M. R., Fazzaro, J., \& Etkin, M. (1968). Anticipatory responding and avoidance discrimination as factors in avoidance conditioning. Joumal of Experimental Psychology, 77, 41-47.

Dieter, S. E. (1977). Preexposure to situational cues and shock intensity in two-way avoidance learning. Animal Learning \& Behavior, 5, 403-406.

Feldman, M. A. (1977). The effect of preexposure to a warning or a safety signal on the acquisition of a two-way avoidance response in rats. Animal Learning \& Behavior, 5, 21-24.

HAMPTON, S. R. (1981). Relationship between preexposure treatments and shock intensity in two-way avoidance learning (Doctoral dissertation, Northern Illinois University, 1980). Dissertation Abstracts International, 41, 4718B.

JACOBS, W. J., LoLordo, V. M. (1977). The sensory basis of avoidance responding in the rat. Learning \& Motivation, 8, 448-466.

JACOBS, W. J., \& LoLoRdo, V. M. (1980). Constraints on Pavlovian aversive conditioning: Implications for avoidance learning in the rat. Learning \& Motivation, 11, 427-455.

Johnson, J. L., \& CHURCH, R. M. (1965). Effects of shock intensity on nondiscriminative avoidance learning of rats in a shuttlebox. Psychonomic Science, 3, 497-498.

Kruger, B. M., Galvani, P. F., Brown, J. S. (1969). A comparison of simulated one-way and shuttle avoidance in an automated apparatus. Behavior Research Methods \& Instrumentation, 1, 143-147.

MCAllister, D. E., McAllister, W. R., \& Dieter, S. E. (1976). Reward magnitude and shock variables (continuity and intensity) in shuttlebox-avoidance learning. Animal Learning \& Behavior, 4, 204-209.

McAllister, W. R., McAllister, D. E., \& Benton, M. M. (1983). Measurement of fear of the conditioned stimulus and of situational cues at several stages of two-way avoidance learning. Learning \& Motivation, 14, 92-106.

McAllister, W. R., McAllister, D. E., Dieter, S. E., \& James, J. H. (1979). Preexposure to situational cues produces a direct relationship between two-way avoidance learning and shock intensity. Animal Learning \& Behavior, 7, 165-173.

MCAllister, W. R., McAlluster, D. E., \& Douglass, W. K. (1971). The inverse relationship between shock intensity and shuttle-box avoidance learning in rats: A reinforcement explanation. Journal of Comparative \& Physiological Psychology, 74, 426-433.

MCAllister, W. R., MCAllister, D. E., Scoles, M. T., \& James, J. H. (1978, NOVEMBER). The influence of prior fear conditioning on avoidance performance. Paper presented at the meeting of the Psychonomic Society, San Antonio, TX.

MODARESI, H. A. (1975). One-way characteristic performance of rats under two-way signaled avoidance conditions. Learning \& Motivation, 6, 484-497.

Mowrer, O. H. (1947). On the dual nature of learning-A reinterpretation of "conditioning" and "problem-solving." Harvard Educational Review, 17, 102-148.

Mowrer, O. H., \& Lamoreaux, R. R. (1951). Conditioning and conditionality (discrimination). Psychological Review, 58, 196-212.

MOYER, K. E., \& KORN, J. H. (1964). Effect of UCS intensity on the acquisition and extinction of an avoidance response. Journal of Experimental Psychology, 67, 352-359.

Scoles, M. T. (1983). An extension of effective reinforcement theory to unsignaled two-way avoidance (Doctoral dissertation, Northern Iflinois University, 1982). Dissertation Abstracts International, 44, 349B.

Seligman, M. E. P., \& Johnston, J. C. (1973). A cognitive theory of avoidance learning. In F. I. McGuigan \& D. B. Lumsden (Eds.), Contemporary approaches to conditioning and learning (pp. 69-110). Washington, DC: Winston.

Theios, J., LyNCH, A. D., \& Lowe, W. F. (1966). Differential effects of shock intensity on one-way shuttle avoidance conditioning. Journal of Experimental Psychology, 72, 294-299.

(Manuscript received August 14, 1985; revision accepted for publication December 12, 1985.) 